\title{
Influence of adding phase change materials on the physical and mechanical properties of cement mortars
}

\author{
Sandra Cunha ${ }^{\mathrm{a}, *}$, Marine Lima ${ }^{\mathrm{b}}$, José B. Aguiar ${ }^{\mathrm{a}}$ \\ ${ }^{a}$ University of Minho, Department of Civil Engineering, Campus de Azurém, 4800-058 Guimarães, Portugal \\ ${ }^{\mathrm{b}}$ University of Nantes, Rue Michel Ange, 58, BP 420, 44606 Saint Nazaire, France
}

\section{H I G H L I G H T S}

- Four compositions were developed with incorporation of non-encapsulated PCM.

- The influence of the non-encapsulated PCM in mortars was evaluated.

- The incorporation of PCM did not affect the density and the mechanical strengths.

- The incorporation of PCM leads to a decrease in the water absorption.

- The ambient temperature did not affect the compressive strength.

\section{A R T I C L E I N F O}

\section{Article history:}

Received 14 January 2016

Received in revised form 20 June 2016

Accepted 28 September 2016

\section{Keywords:}

Mortars

Cement

Phase change materials

Physical properties

Mechanical properties

\begin{abstract}
A B S T R A C T
During the last years several studies of construction materials with incorporation of encapsulated phase change material (PCM) have been published. However, the utilization of non-encapsulated PCM is one of the main gaps. The main objective of this work was the study of physical and mechanical properties of cement mortars with incorporation of non-encapsulated PCM. It was possible to conclude that the utilization of non-encapsulated phase change materials can be seen as a good and more economical solution for the energy efficiency of the buildings, without prejudice of the properties.
\end{abstract}

다 2016 Elsevier Ltd. All rights reserved.

\section{Introduction}

The rapid world economic growth has led to an increase in the energy consumption. The fossil fuels dominate the world energy market, with a share of about $81 \%$ [1]. However, the fossil fuels are running out and present high costs. On the other hand, its use is related with the emission of harmful gases into the environment. Thus, the energy efficient use and the possibility of the use of renewable sources of energy are becoming increasingly important.

The energy efficiency of buildings is now one of the main objectives of regional, national and international energy policy [2]. Buildings are one of the leading sectors in energy consumption in developed countries. In the European Union the buildings represent $40 \%$ of energy consumption and $\mathrm{CO}_{2}$ emissions to the atmosphere [3-4].

\footnotetext{
* Corresponding author.

E-mail addresses: sandracunha86@gmail.com (S. Cunha), marine-23-02@ hotmail.fr (M. Lima), aguiar@civil.uminho.pt (J.B. Aguiar).
}

The solutions based into the use of renewable energy contribute to the increase the energy efficiency, to decrease the use of fossil fuel reserves and to reduce the pollutant emissions into the atmosphere. The utilization of renewable energy sources, like solar energy, is becoming a crucial measure promoting energy efficiency and sustainability of buildings. In addition, the use of renewable energy sources is a key factor to reduce the energy dependence of the buildings. Therefore, the heat storage possible with phase change materials is a strategy for the development of construction projects with high energy performance.

The phase change materials have the ability to reduce the temperature variation, due to their capability in absorbing and releasing energy to the environment. The PCM operating principle consists in change their status, according to the environment temperature. The PCMs absorb and store energy, suffering a change from a solid state to a liquid state, while temperature increases. On the other hand, the material possesses the capability to release the previously stored energy when the temperature decreases, suffering in this case a change from a liquid state to a solid state [4-6]. 
The PCM can be incorporated into building materials using different methods, such as encapsulation, shape-establization, direct incorporation and absorption by immersion or capillarity [1,7-12]. The most common form of this material utilization is the encapsulation. There are two types of encapsulation: macroencapsulation and microencapsulation [7-8]. Cunha et al. [13], developed a study dealing with the incorporation of microencapsulated PCM in mortars based in different binders. They concluded that the incorporation of PCM in mortars causes significant changes in their properties in fresh and hardened state, such as an increase in the amount of water added to the mortar and a decrease of the mechanical strengths. The shape-stabilized PCM is prepared by integrating the PCM into the supporting material. The shape-stabilized PCM are mainly classified as composite PCM and are fabricated by embedding PCM into shape stabilization supports such as high density polyethylene, styrene, polystyrene resin, etc. However, this process is complex [9]. In the absorption by immersion, the construction product is immersed in the liquid PCM [8]. Hawes et al. [11] developed a study in order to examine the PCM absorption mechanisms in concrete to achieve the diffusion of the desired PCM amount and hence the required thermal storage capacity.

It should be noted that currently there are still high production costs for the encapsulation of PCM. Taking into account the current costs in the market, the cost of the non-encapsulated PCM is about 7 times lower than the cost of the microencapsulated PCM. Thus, it becomes urgent the development of new construction materials based in techniques and raw materials, with high thermal performance at low cost. These solutions become extremely competitive when compared with traditional solutions with low contribution to energy efficiency. It is imperative the development of mortars for interior coating with incorporation of PCM based on inexpensive raw materials (non-encapsulated PCM), contradicting the production costs of materials based on macro or microencapsulated PCM.

During the last years, several studies of construction materials with incorporation of encapsulated PCM have been published. The incorporation of PCM microcapsules in gypsum plaster boards [14-17], concrete and mortars based in different binders has been a target of recent investigations [13,18-20]. Other studies were also published such as incorporation of PCM in PVC panels, blocks and bricks [21-23].

The main objective of this work was the study of the influence of incorporation of non-encapsulated phase change materials in mortars, evaluating their physical and mechanical properties. Other objective was the evaluation of the possible PCM leakage from the interior of the mortars. Thus, several tests were performed with 4 different compositions at 3 different ambient temperatures $\left(10^{\circ} \mathrm{C}, 25^{\circ} \mathrm{C}\right.$ and $\left.40^{\circ} \mathrm{C}\right)$. The proportion of PCM studied was $0 \%, 2.5 \%, 5 \%$ and $7.5 \%$ of the sand mass. Some properties were evaluated, in the fresh and hardened state, such as workability, density, water absorption by capillarity, water absorption by immersion, microstructure, hydration process, flexural strength and compressive strength.

\section{Experimental program}

\subsection{Materials}

Cement based mortars were developed in order to understand the influence of adding non-encapsulated phase change materials. The materials selection for this research was based in other works developed by the authors $[4,13,20,24]$.

The used cement was CEM II B-L 32.5N with density of $3030 \mathrm{~kg} /$ $\mathrm{m}^{3}$. The sand used has an average particle size of $439,9 \mu \mathrm{m}$ and a density of $2600 \mathrm{~kg} / \mathrm{m}^{3}$. Synthetic fibers of polyamide with a length of $6 \mathrm{~mm}, 22.3 \mu \mathrm{m}$ of thickness and density of $1380 \mathrm{~kg} / \mathrm{m}^{3}$, were used. The superplasticizer used was a polyacrylate, with a density of $1050 \mathrm{~kg} / \mathrm{m}^{3}[4,13,20,24]$.

Finally the PCM used is non-encapsulated, composed by paraffin with temperature transition between 20 and $23^{\circ} \mathrm{C}$, enthalpy of $200 \mathrm{~kJ} / \mathrm{kg}$, density in solid state of $760 \mathrm{~kg} / \mathrm{m}^{3}$ and in liquid state of $700 \mathrm{~kg} / \mathrm{m}^{3}[25]$.

\subsection{Compositions}

Four compositions were developed with the main goal to evaluate the possibility of use non-encapsulated PCM in interior coating mortars. These compositions were evaluated from the fresh state up to 28 days. The studied compositions are presented in Table 1 . The PCM content was fixed in $0 \%, 2.5 \%, 5 \%$ and $7.5 \%$ of aggregate mass.

\subsection{Test procedures}

The developed mortars were evaluated in the fresh and hardened state. In the fresh state the workability was determined. In hardened state, the density, water absorption by capillarity, water absorption by immersion, microstructure, hydration process, flexural strength and compression strength, were evaluated.

The density, water absorption by capillarity, water absorption by immersion, flexural strength and compression strength were performed with the specimens at three different temperatures. So, the specimens were maintained, during $24 \mathrm{~h}$, before the tests, at three different ambient temperatures with resource to an oven and a climatic chamber. The temperatures tested were $25^{\circ} \mathrm{C}$ (reference temperature), $10^{\circ} \mathrm{C}$ and $40^{\circ} \mathrm{C}$. These temperatures were selected taking into account the PCM transition temperature. Therefore, the tests were performed for the different mortars with $\mathrm{PCM}$ in the solid state $\left(10^{\circ} \mathrm{C}\right)$, with the PCM in the transition state $\left(25^{\circ} \mathrm{C}\right)$ and with the PCM in the liquid state $\left(40^{\circ} \mathrm{C}\right)$. Thus, it was possible to evaluate the influence of adding PCM non-encapsulated in mortars, but also the influence of the PCM state in the physical and mechanical properties of the mortars.

The test procedures used for characterize the physical and mechanical properties of the developed mortars were based in European standards and other works developed by the research team $[4,24]$.

Based on the European standard EN 1015-3 [26], the workability tests were performed by flow tests. The resulting value was only considered when equal to $160 \pm 5 \mathrm{~mm}$.

After the preparation, all the specimens were stored during 7 days in polyethylene bags and subsequently placed in the room with temperature of about $22^{\circ} \mathrm{C}$ and $65 \%$ of humidity during 21 days, according to the standard EN 1015-11 [27].

The observation of the microstructure of developed mortars was performed using a scanning electron microscope. For each composition, two cylindrical specimens with diameter and height of approximately $1 \mathrm{~cm}$ were prepared [24].

The products present in the hardened mortars were evaluated with thermogravimetric tests (DSC-TGA). The tests were performed in argon atmosphere, with flow rate of $100 \mathrm{ml} / \mathrm{min}$ and heating rate of $10^{\circ} \mathrm{C} / \mathrm{min}$ in a range of temperature between $22{ }^{\circ} \mathrm{C}$ and $1000^{\circ} \mathrm{C}$. The test sample mass was $0.2 \mathrm{~g}$ of material removed from the surface of the specimen, at 28 days.

The water absorption by capillarity tests were performed based on the European standard EN 1015-18 [28]. The water absorption by immersion tests were based on the specification LNEC E 394 [29]. The tests were performed in three different temperatures 
Table 1

Mortars formulation $\left(\mathrm{kg} / \mathrm{m}^{3}\right)$.

\begin{tabular}{|c|c|c|c|c|c|c|}
\hline Composition & Cement & Sand & PCM & Superplasticizer & Fibers & Water \\
\hline CEM-OPCM & 500 & 1279.4 & 0 & 15 & 5 & 325 \\
\hline CEM-2.5PCM & 500 & 1289.6 & 32.2 & 15 & 5 & 275 \\
\hline CEM-5PCM & 500 & 1243.5 & 62.2 & 15 & 5 & 250 \\
\hline CEM-7.5PCM & 500 & 1204 & 90.3 & 15 & 5 & 225 \\
\hline
\end{tabular}

$\left(10^{\circ} \mathrm{C}, 25^{\circ} \mathrm{C}\right.$ and $\left.40^{\circ} \mathrm{C}\right)$. The samples were obtained by cutting the prismatic specimens with dimensions of $40 \times 40 \times 160 \mathrm{~mm}^{3}$, previously subjected to flexural tests, according to the specifications $[28,29]$. Regarding the water absorption by capillarity tests, the quantification of the absorbed water was performed by conducting successive weightings, according to a previously established plan $[24,28]$. Relatively to the water absorption by immersion tests, the specimens were dried in an oven, at $105^{\circ} \mathrm{C}$, until the constant mass. Subsequently, they were immersed into a container with water. Finally, after saturation, the hydrostatic mass was determined [24,29].

The flexural and compressive behavior was determined based on the standard EN 1015-11 [27]. The tests were performed immediately after submitting the specimens during $24 \mathrm{~h}$ at three different temperatures $\left(10^{\circ} \mathrm{C}, 25^{\circ} \mathrm{C}\right.$ and $\left.40^{\circ} \mathrm{C}\right)$. The flexural tests were performed with load control at a speed of $50 \mathrm{~N} / \mathrm{s}$. The compressive tests were performed with load control at a speed of $150 \mathrm{~N} / \mathrm{s}$ [24,27].

\section{Test results and discussion}

\subsection{Workability}

The workability tests were performed with the main goal to verify the application adequacy of the developed mortars $[4,13,20,24]$. According to Fig. 1, it was observed a decrease superior to $15 \%$ in the water content with the incorporation of $2.5 \%$ of PCM.

Fig. 2 presents the liquid material/binder ratio. It was observed that the incorporation of non-encapsulated PCM did not cause significate changes in the liquid material/binder ratio. This behavior can be justified by the utilization of the liquid PCM, which in part can operate as agent for the formation of a homogeneous mortar, replacing part of the water.

Other studies related with the incorporation of PCM microcapsules in mortars reveals an increase in the water content, which is

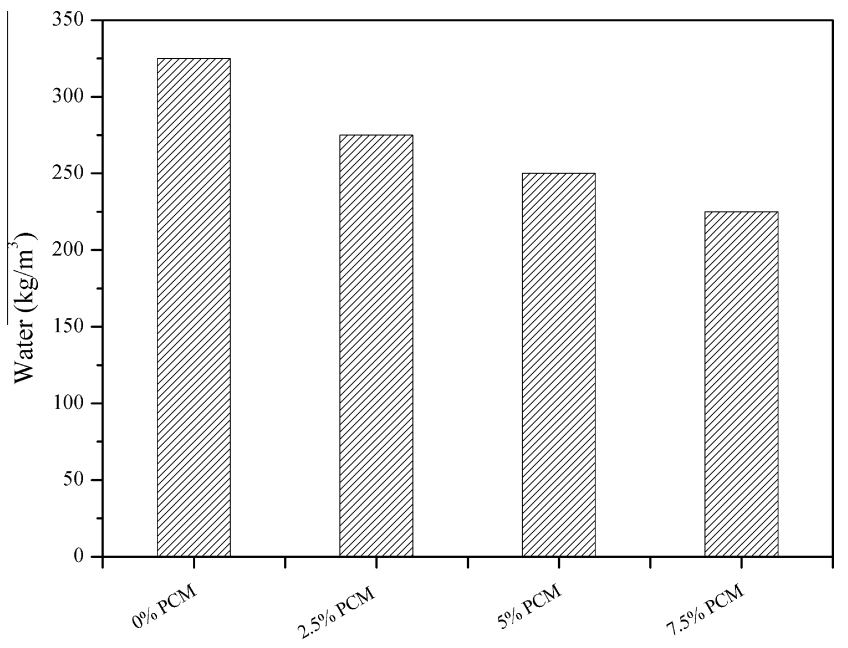

Fig. 1. Water content of the mortars.

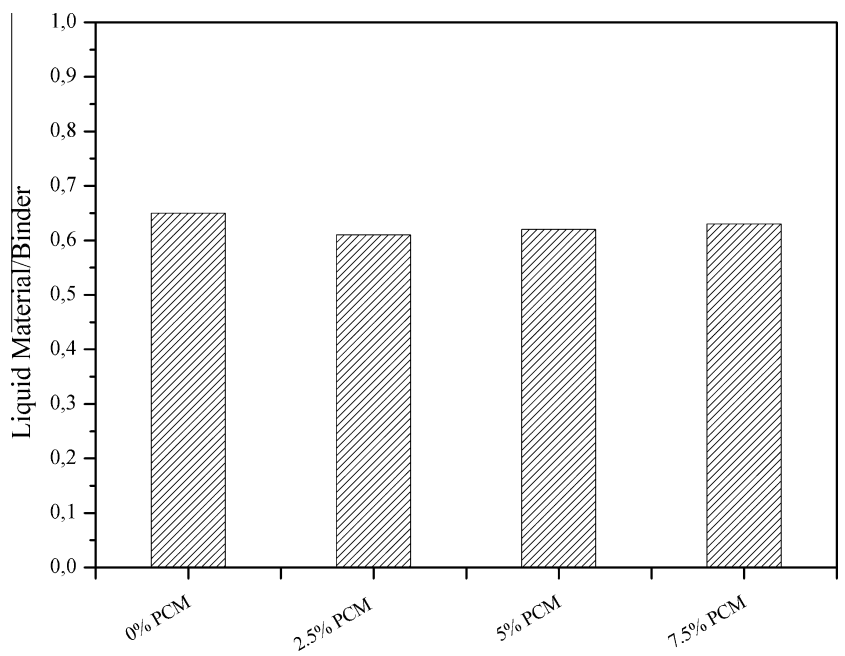

Fig. 2. Liquid material - binder ratio of the mortars.

related with the reduced particle dimension of the used PCM and by the possible water absorption of the polymeric wall of the microcapsule $[4,13,20]$. Thus, it was possible to predict that the mortars with incorporation of non-encapsulated PCM will show lower porosity when compared to the mortars with incorporation of microencapsulated PCM.

\subsection{Density}

Regarding the density, it was observed that the incorporation of non-encapsulated PCM did not cause significant changes (Fig. 3). The mortars tested at different temperatures did not present changes in the density, because the densities of the PCM, in the liquid and solid states, are similar.

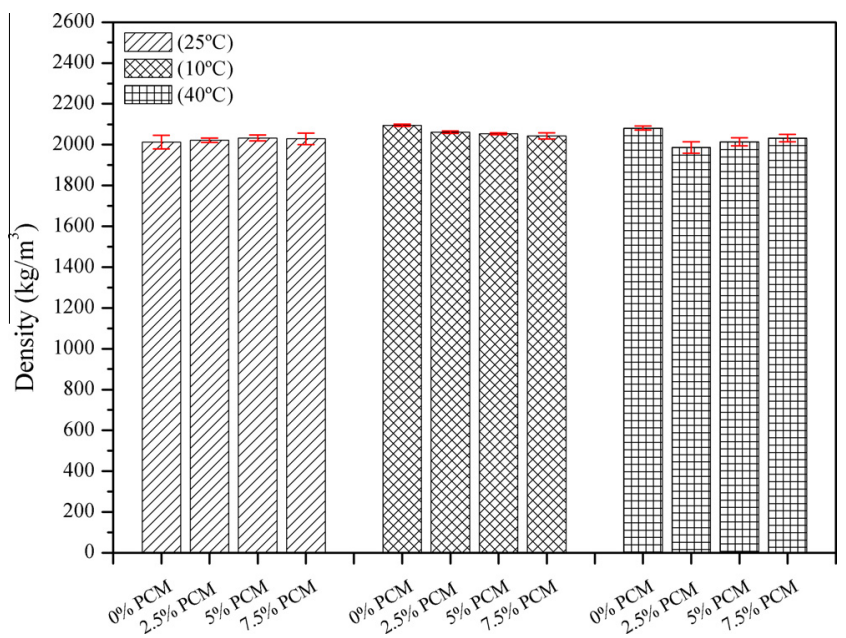

Fig. 3. Density of the mortars. 

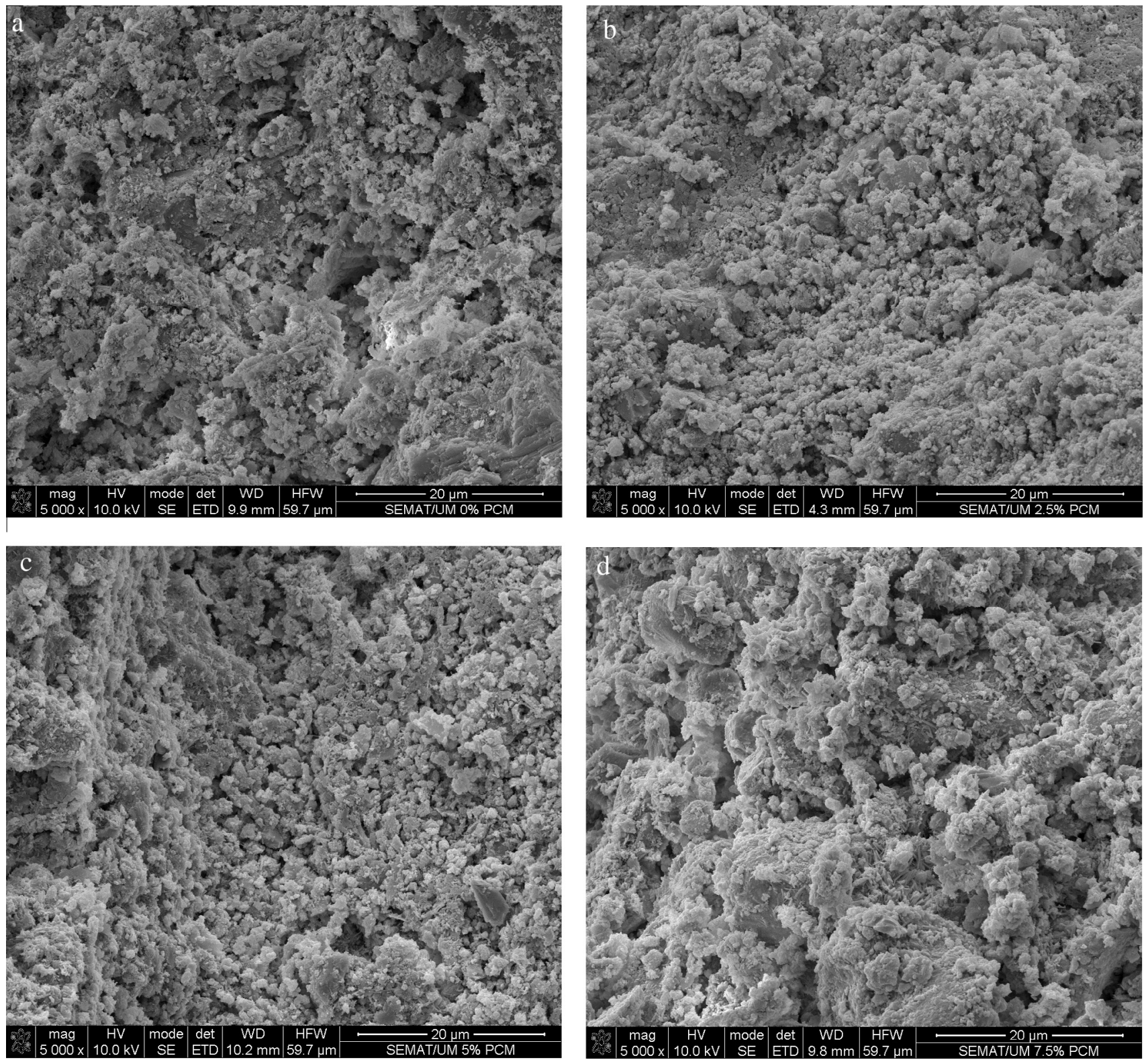

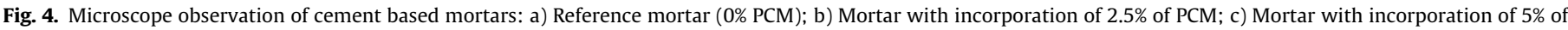
PCM; d) Mortar with incorporation of $7.5 \%$ of PCM.

\subsection{Microstructure}

The scanning electron microscope observations allow to observe the existence of possible incompatibilities between the different materials present in the mortars. Fig. 4 shows the microstructure of the cement based mortars with different contents of non-encapsulated PCM. These observations reveal a good link between the different materials (PCM, fibers, aggregate and binder) evidenced by the absence of cracks in the microstructure of the developed mortars which demonstrates an adequate process of mixing, application and curing of the mortars.

Other observations were performed in order to evaluate the micropore distribution in the different mortars. In the mortars with incorporation of PCM it was observed a decrease in the quantity of the pores and a decrease in its size (Fig. 5). The mortar with incorporation of $7.5 \%$ of PCM presents a more compact microstructure when compared to the reference mortar (0\% PCM). This behavior can be explained by the decrease of water content of the mortars with PCM incorporation.

It was also possible to identify that the mortars without addition of PCM present a denser microstructure, resulting from the increase cement hydration, when compared with the mortars with PCM incorporation (Fig. 6). This behavior can be justified by the presence of the PCM that difficult the contact of cement particles with water and air.

The products present in the hardened mortars can be determined using DSC-TGA tests. According with Figs. 7-10 it was observed an increase in the number of peak points with the increase of incorporation of non-encapsulated PCM. Thus, it was possible to conclude that the incorporation of PCM leads to changes in the hydration products of the cement mortars, as mentioned earlier.

Regarding to the reference mortars (Fig. 7) it was possible to observe 2 different peak points at $80^{\circ} \mathrm{C}$ and at $761{ }^{\circ} \mathrm{C}$. The first peak point $\left(80^{\circ} \mathrm{C}\right)$ is related to the loss of uncombined water, 

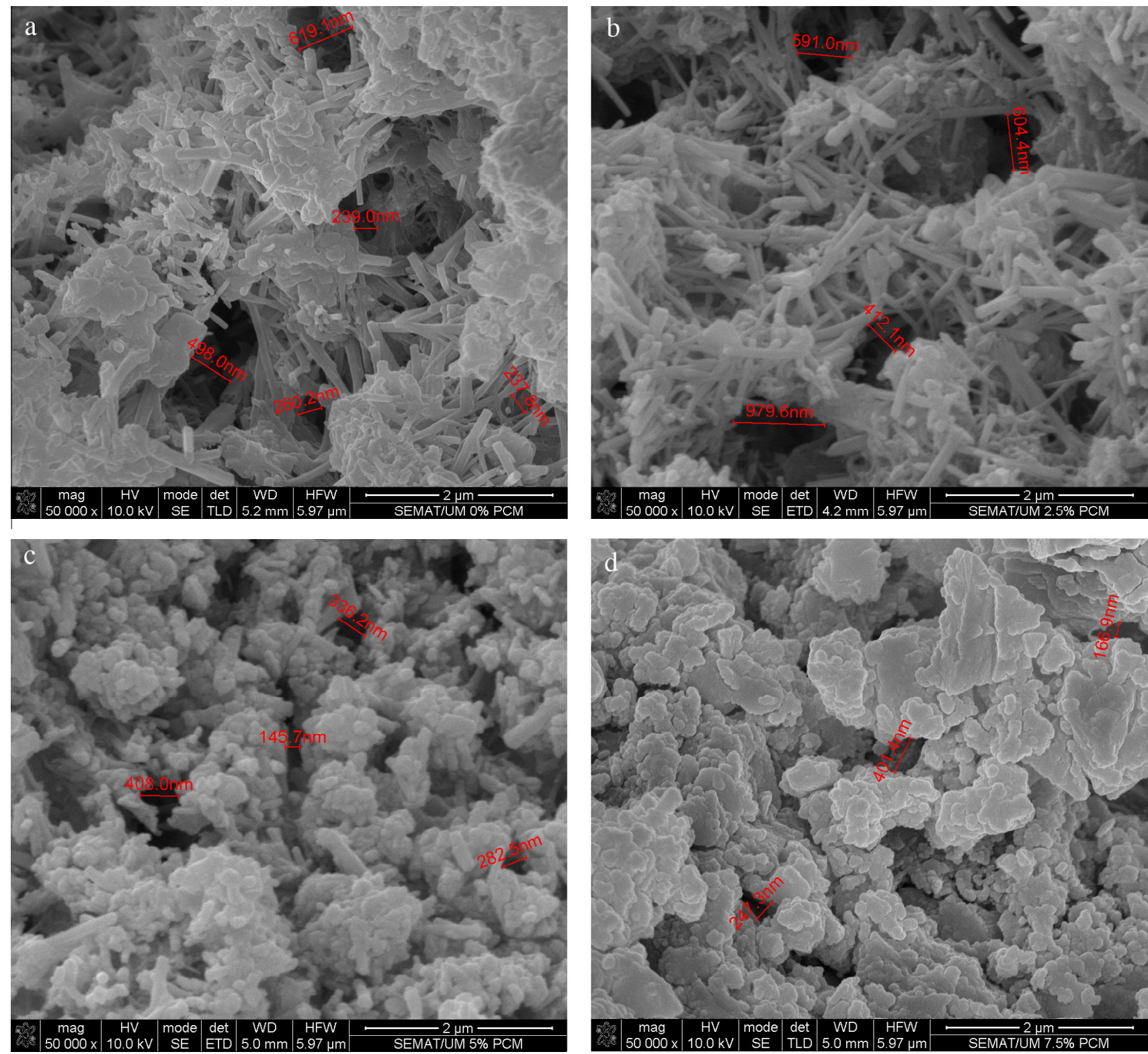

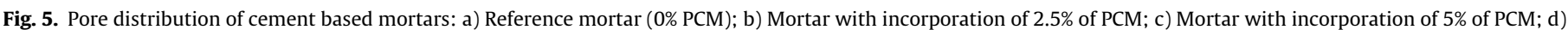
Mortar with incorporation of $7.5 \%$ of PCM.

which occurs between 0 and $105^{\circ} \mathrm{C}$. The free water or not chemically combined water present in mortars is lost at two different stages. The first stage occurs between $35^{\circ} \mathrm{C}$ and $70^{\circ} \mathrm{C}$, where the water present in the large dimensions pores evaporates. In the second stage, which occurs between 70 and $105^{\circ} \mathrm{C}$, there is the liberation of water retained by capillary pressure in the capillary pores [30-33]. The second peak, that occurs at $761{ }^{\circ} \mathrm{C}$, is related with the decarbonation of calcium carbonate $\left(\mathrm{CaCO}_{3}\right)$ [30,34].

Fig. 8 presents the obtained results for mortars with incorporation of $2.5 \%$ of non-encapsulated PCM. It was verified different peak points at $89{ }^{\circ} \mathrm{C}, 202^{\circ} \mathrm{C}$ and $746^{\circ} \mathrm{C}$. As mentioned before, the peak point corresponding to $89^{\circ} \mathrm{C}$ is related with the loss of uncombined water present in the sample and the peak point corresponding to a temperature of $746{ }^{\circ} \mathrm{C}$ is related to the decarbonation of calcium carbonate. The peak point at a temperature of $202{ }^{\circ} \mathrm{C}$ is related to the flash point of the PCM present in the sample [25].
Fig. 9 presents the DCS-TGA test results for mortars with incorporation of 5\% of PCM. It was observed the existence of 5 different peak points at temperatures of $87^{\circ} \mathrm{C}, 210^{\circ} \mathrm{C}, 431^{\circ} \mathrm{C}$, $494^{\circ} \mathrm{C}$ and $750{ }^{\circ} \mathrm{C}$. As mentioned before the peak point at $87^{\circ} \mathrm{C}$ is related with the loss of uncombined water, the peak point at $210{ }^{\circ} \mathrm{C}$ is related with the flash point of PCM and the peak point at $750^{\circ} \mathrm{C}$ is related with the decarbonation of calcium carbonate. However, two different peak points were marked $\left(431^{\circ} \mathrm{C}\right.$ and $494^{\circ} \mathrm{C}$ ), which are related with the dehydroxylation of calcium hydroxide $\left(\mathrm{Ca}(\mathrm{OH})_{2}\right)$. The decomposition of calcium hydroxide $\left(\mathrm{Ca}(\mathrm{OH})_{2}\right)$ into calcium oxide and water $\left(\mathrm{CaO}+\mathrm{H}_{2} \mathrm{O}\right)$ is characterized by a loss of mass between the temperature range of $425-550^{\circ} \mathrm{C}$ [30]. Finally, Fig. 10 shows the obtained results for mortars with incorporation of $7.5 \%$ of PCM. It was also observed 5 different peak points at similar temperatures $\left(99^{\circ} \mathrm{C}, 232^{\circ} \mathrm{C}\right.$, $400{ }^{\circ} \mathrm{C}, 467^{\circ} \mathrm{C}$ and $750{ }^{\circ} \mathrm{C}$ ). Thus, the peak point at $99^{\circ} \mathrm{C}$ corresponds to the uncombined water, the peak point at $232^{\circ} \mathrm{C}$ is related with the flash point of $\mathrm{PCM}$, the peak point at $400{ }^{\circ} \mathrm{C}$ 

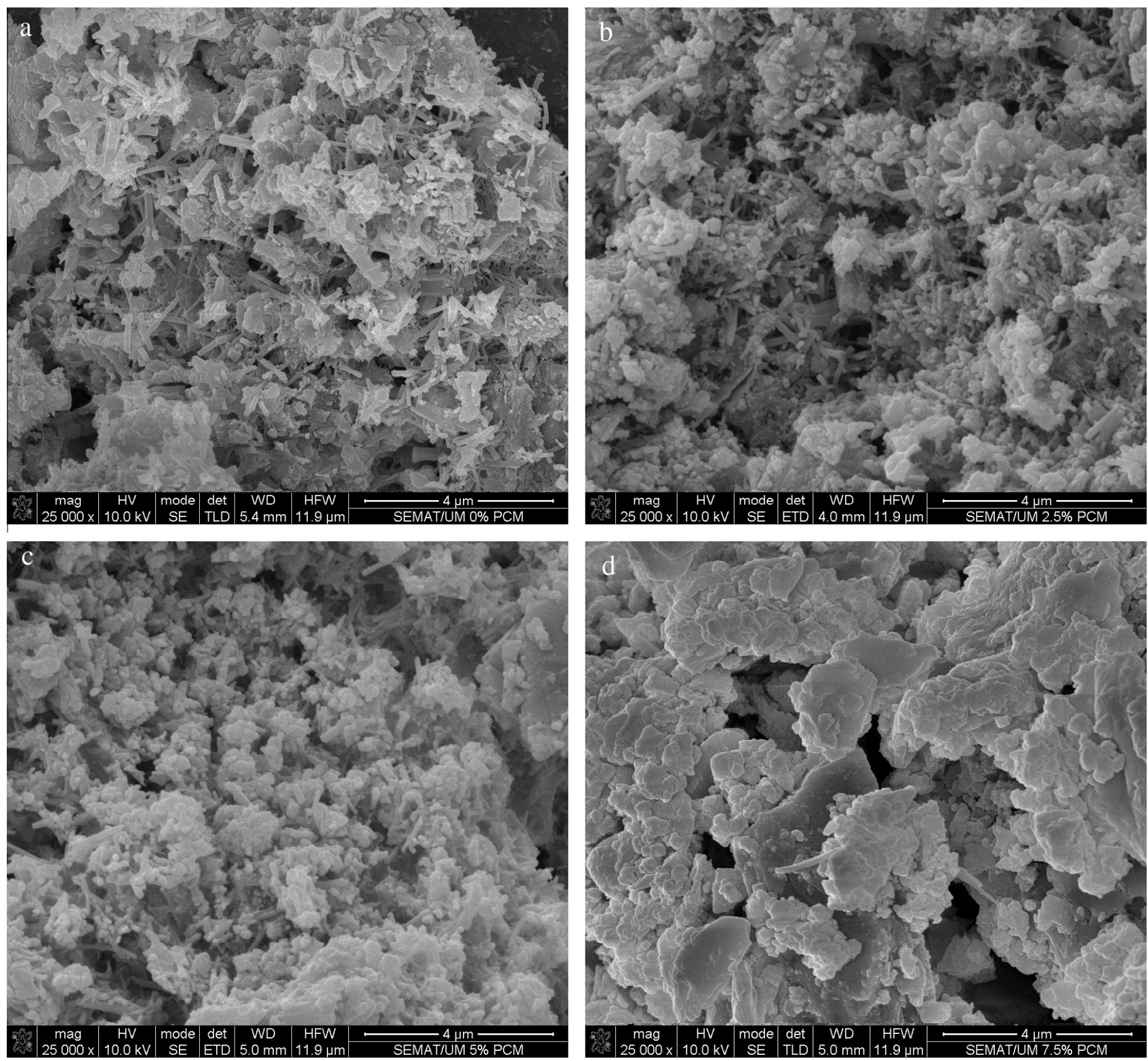

Fig. 6. Microstructure of cement based mortars: a) Reference mortar ( $0 \%$ PCM); b) Mortar with incorporation of $2.5 \%$ of PCM; c) Mortar with incorporation of $5 \%$ of PCM; d) Mortar with incorporation of $7.5 \%$ of PCM.

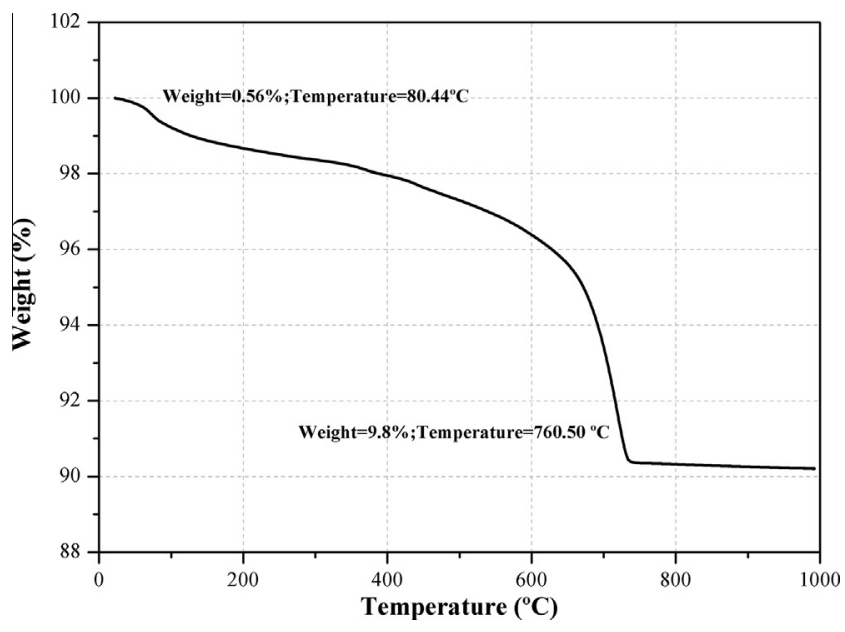

Fig. 7. DSC-TGA test for reference mortar (0\% PCM).

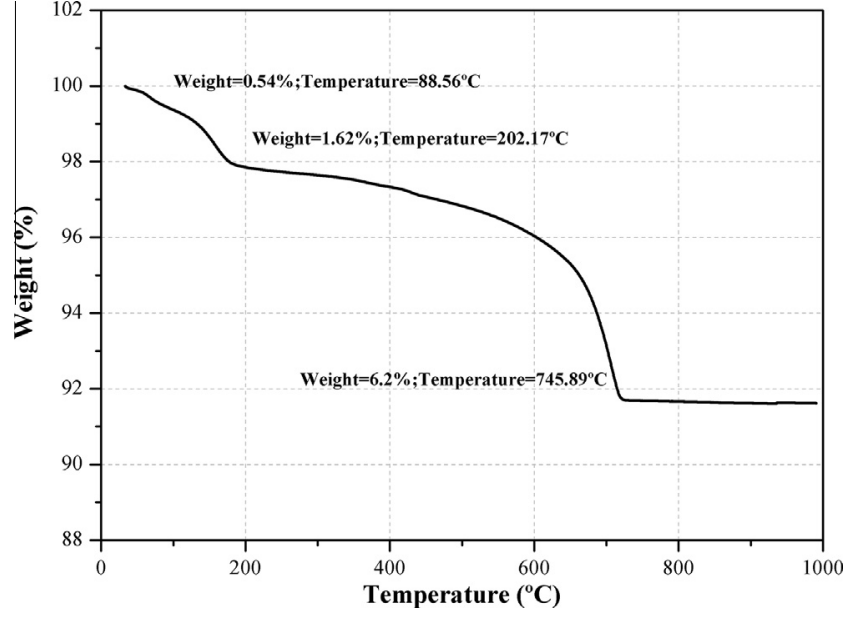

Fig. 8. DSC-TGA test for the mortar with incorporation of $2.5 \%$ of PCM. 


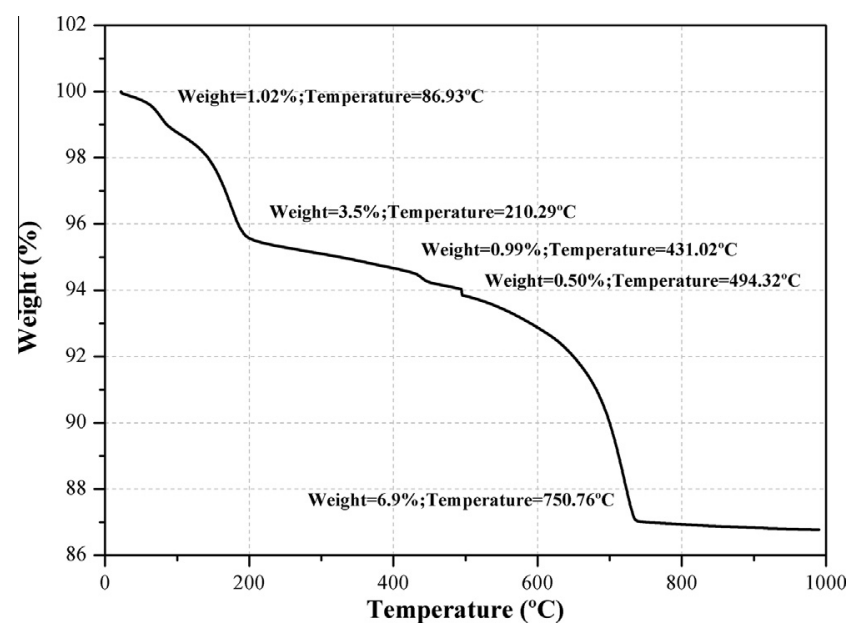

Fig. 9. DSC-TGA test for the mortar with incorporation of $5 \%$ of PCM.

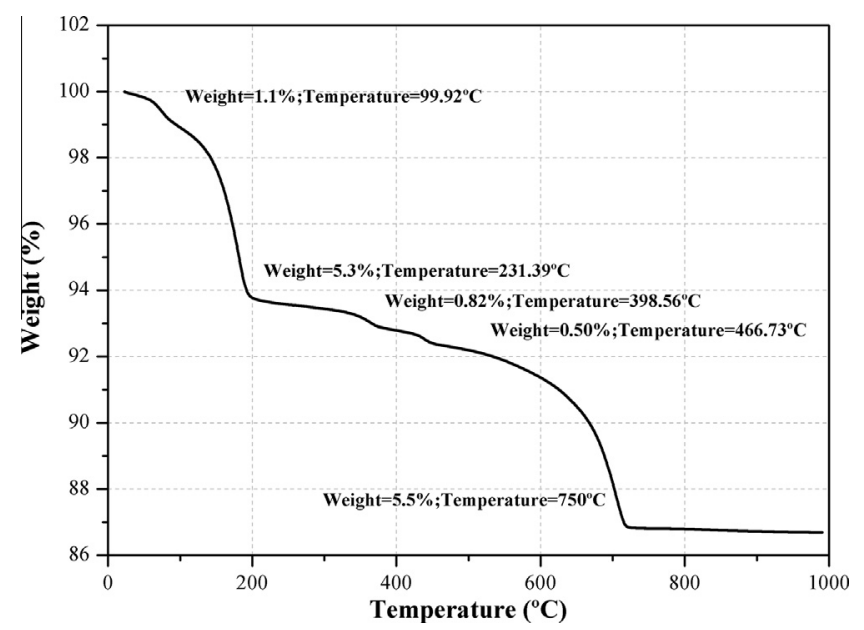

Fig. 10. DSC-TGA test for the mortar with incorporation of $7.5 \%$ of PCM.

and $467{ }^{\circ} \mathrm{C}$ is the decomposition of calcium hydroxide $\left(\mathrm{Ca}(\mathrm{OH})_{2}\right)$ and the peak point at $750{ }^{\circ} \mathrm{C}$ is related with the decarbonation of calcium carbonate $\left(\mathrm{CaCO}_{3}\right)$.

Briefly, it was possible to observe the presence of calcium hydroxide in mortars with incorporation of $5 \%$ and $7.5 \%$ of nonencapsulated PCM. The presence of calcium hydroxide in these mortars indicates a delay in the cement hardener process, as indicated by the absence of crystals in the microscope observations (Fig. 6). This behavior can be justified by the PCM presence that difficult the cement contact with water and air, which retards the cement hardener reactions.

\subsection{Water absorption by capillarity}

According to Fig. 11, it was verified that the incorporation of non-encapsulated PCM leads to a decrease in the capillary absorption coefficient superior to $72 \%$. This behavior can be explained by the partial or total occupation of the mortar pores by the PCM. It was also verified that the mortars with PCM incorporation present a similar capillary absorption coefficient when submitted to different ambient temperatures, which shows that even in different states (solid and liquid) the PCM does not move to outside of the mortar matrix. Regarding the

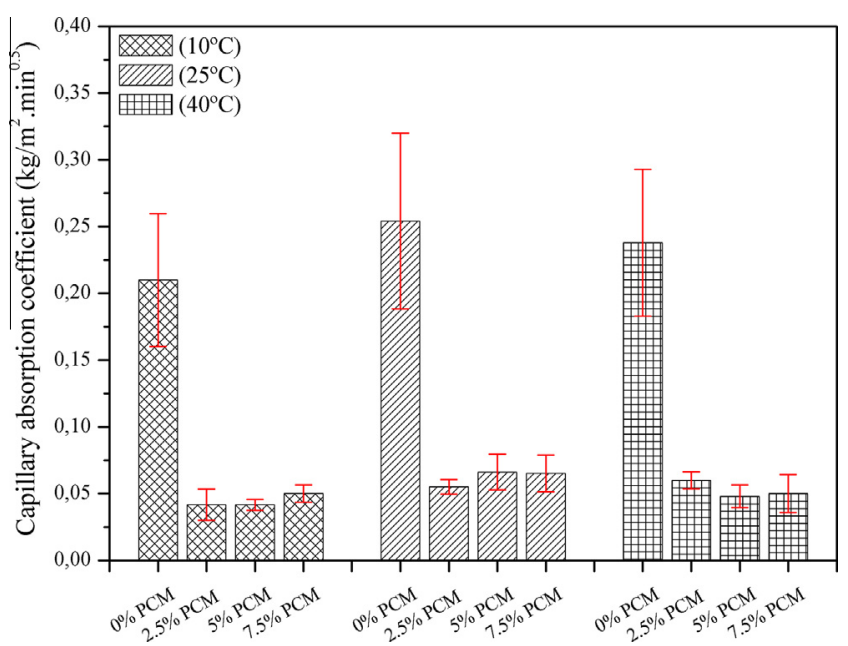

Fig. 11. Capillary absorption coefficient of the mortars.

reference mortars $(0 \% \mathrm{PCM})$, it was observed a higher capillary absorption coefficient, due to the presence of empty pores in the mortars.

Fig. 12 shows the behavior of the studied mortars during 7 days of testing. According to the results of the capillary absorption coefficient, it was observed that the mortars without incorporation of PCM presented a higher capacity of water absorption, due to the higher quantity of free pores in their microstructure. On the other hand, in each formulation it was observed a slightly different capacity of water absorption taking into account the environment temperature of the test. The mortars subjected to low temperatures $\left(10^{\circ} \mathrm{C}\right)$ exhibit a lower capacity of capillary water absorption, due to the PCM solid state, decreasing contention water capacity in the pores of the mortars. The mortars submitted to temperatures that allow the PCM transition from solid state to liquid state $\left(25^{\circ} \mathrm{C}\right.$ and $\left.40^{\circ} \mathrm{C}\right)$ presented a higher capacity of capillary water absorption, due to the smaller volume that the PCM occupies in the mortar pores.

\subsection{Water absorption by immersion}

According to Fig. 13, it was observed a decrease in the water absorption by immersion with the incorporation of PCM. The incorporation of $2.5 \%$ of non-encapsulated PCM leads to a decrease superior to $17 \%$. It was also verified that the specimens exposure to lower temperatures $\left(10^{\circ} \mathrm{C}\right)$ decreases the capacity of water absorption by immersion of the mortars. This situation can be explained by the solid state of the PCM inside the pores of the mortars. On the other hand, these results when compared with the similar results for mortars with incorporation of microencapsulated PCM reveals lower values of water absorption $[4,13]$. Thus, it is possible to conclude that the mortars with incorporation of microencapsulated PCM have higher porosity, due to the increase in their water content.

\subsection{Flexural and compressive behavior}

Fig. 14 shows the flexural and compressive behavior of the different mortars when exposed to different ambient temperatures. It was observed that the incorporation of $2.5 \%$ of non-encapsulated PCM did not cause significant changes in the flexural and compressive behavior. This situation can be explained by the contained PCM inside the pores, not 

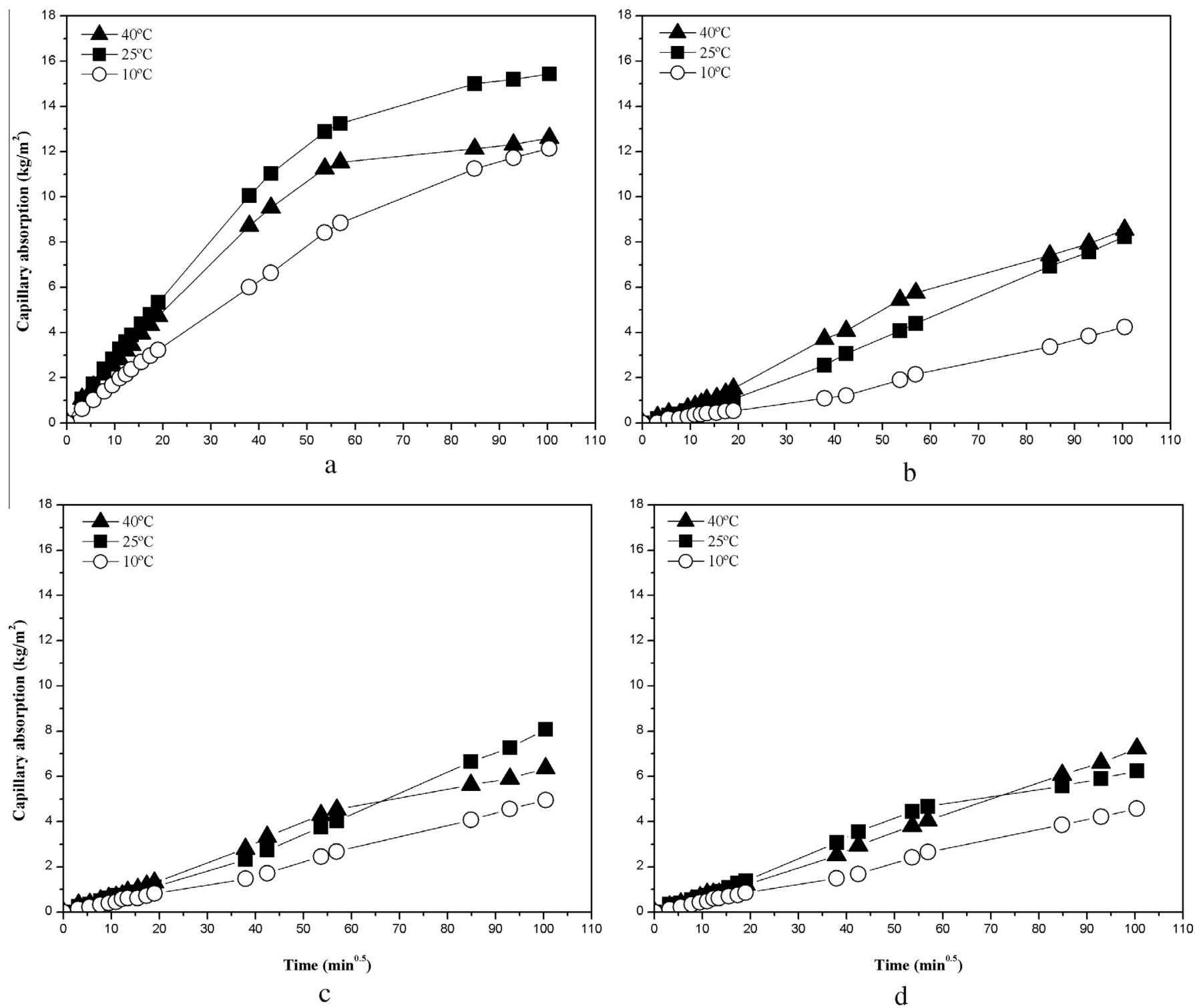

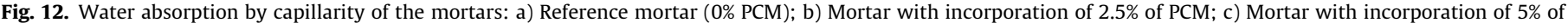
PCM; d) Mortar with incorporation of $7.5 \%$ of PCM.

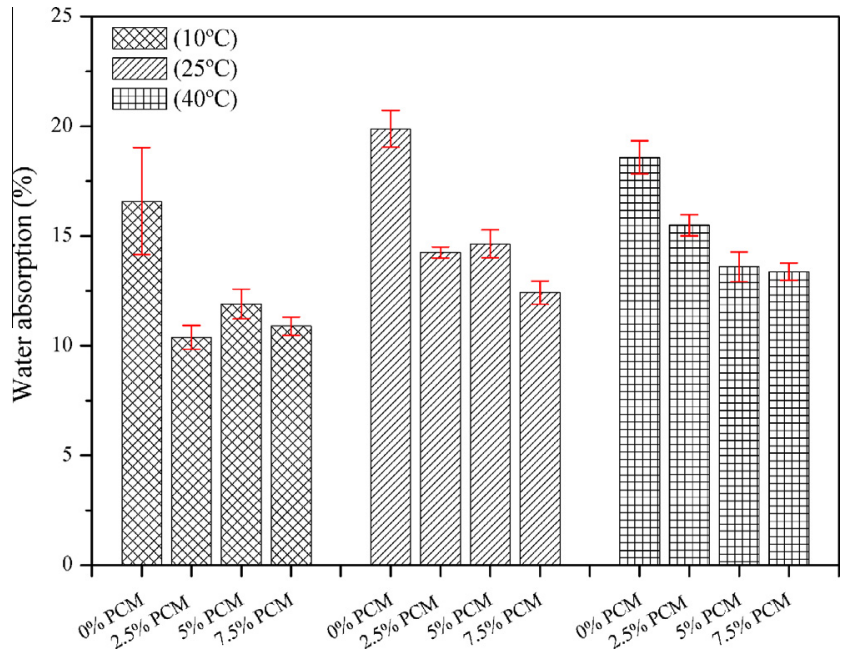

Fig. 13. Water absorption by immersion of the mortars. weakening the mechanical strength. On the other hand, it was verified a liquid material/binder ratio similar for all compositions.

Studies related with the incorporation of PCM microcapsules in mortars showed a decrease in the flexural and compressive strengths, due to the presence of higher water content in the mortars $[4,13,20]$. Thus, it was verified that the incorporation of non-encapsulated PCM is a solution with no significant impact in the main mechanical properties of the mortars.

The mortars were classified according to standard NP EN 998-1 (Table 2), taking into account the compressive strength [35]. The aim of this work was to obtain cement mortars with incorporation of non-encapsulated PCM for interior coating with an appropriate classification. It was observed that all developed mortars presented the maximum classification of CSIV (Table 3). Thus, it is possible to obtain a mortar incorporating non-encapsulated PCM with appropriated mechanical behavior. 


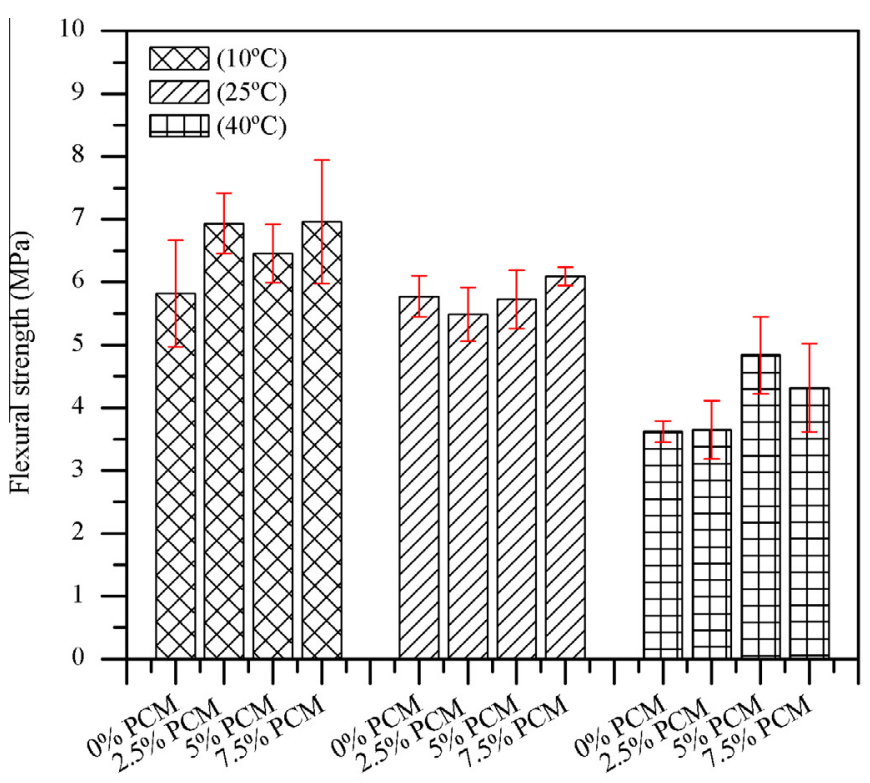

a

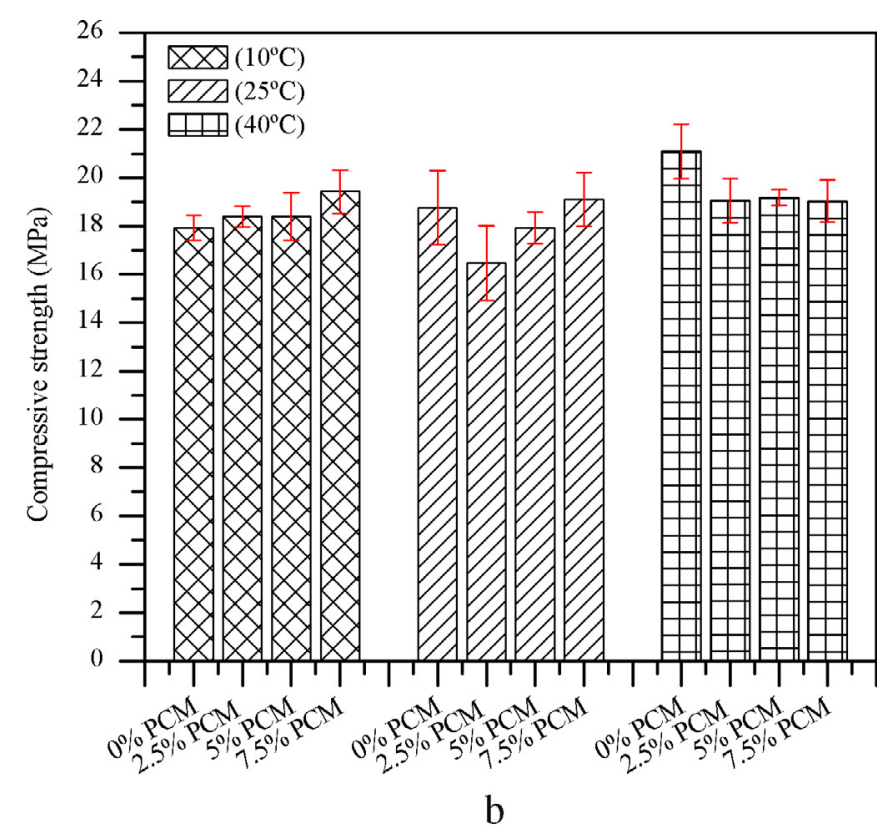

Fig. 14. Mechanical behavior of the mortars: a) Flexural strength; b) Compressive strength.

Table 2

Classification of mortars according to standard NP EN 998-1:2010 [35].

\begin{tabular}{ll}
\hline Class of strength & Compressive strength (MPa) \\
\hline CSI & $0.4-2.5$ \\
CSII & $1.5-5.0$ \\
CSIII & $3.5-7.5$ \\
CSIV & $\geqslant 6.0$ \\
\hline
\end{tabular}

Table 3

Classification of mortars according with the compressive strength.

\begin{tabular}{llll}
\hline Composition & $\begin{array}{l}\text { Test } \\
\text { temperature }\left({ }^{\circ} \mathrm{C}\right)\end{array}$ & $\begin{array}{l}\text { Compressive } \\
\text { strength }(\mathrm{MPa})\end{array}$ & $\begin{array}{l}\text { Classification NP EN } \\
998-1: 2010\end{array}$ \\
\hline CEM-0PCM & 10 & $19.93 \pm 0.52$ & CSIV \\
CEM-2.5PCM & & $18.40 \pm 0.43$ & \\
CEM-5PCM & & $18.39 \pm 0.98$ & \\
CEM-7.5PCM & & $19.43 \pm 0.90$ & \\
CEM-0PCM & 25 & $18.76 \pm 1.55$ & CSIV \\
CEM-2.5PCM & & $17.00 \pm 1.55$ & \\
CEM-5PCM & & $17.92 \pm 0.65$ & \\
CEM-7.5PCM & & $19.11 \pm 1.11$ & \\
CEM-0PCM & 40 & $21.34 \pm 1.13$ & CSIV \\
CEM-2.5PCM & & $19.06 \pm 0.91$ & \\
CEM-5PCM & & $19.17 \pm 0.33$ & \\
CEM-7.5PCM & & $19.04 \pm 0.87$ & \\
\hline
\end{tabular}

\section{Conclusion}

This study evaluated the physical and mechanical properties of cement mortars with incorporation of non-encapsulated PCM. Based on the obtained results, it can be concluded that the addition of these materials caused some changes in the cement mortars properties in fresh and hardened state.

The incorporation of non-encapsulated PCM causes a decrease in the amount of water added to the mixture, in order to maintain the same workability. However, the ratio liquid material/binder of the mortars is similar. This indicates that in general all mortars require the same amount of liquid (water and PCM) to form an homogeneous paste.
It was possible to conclude that the incorporation of nonencapsulated PCM leads to a decrease in the microporosity of mortars and a delay in the cement hardener process, such as it was demonstrated by scanning electron microscope observations and DSC-TGA tests.

Regarding the water absorption by capillarity it was observed that the incorporation of non-encapsulated PCM leads to a decrease in the capillary absorption coefficient, due to the partial or total occupation of the mortar pores by the PCM. The water absorption by immersion presents a decrease with the incorporation of non-encapsulated PCM. The mortars behavior with addition of non-encapsulated PCM are similar, however some changes can be detected with the ambient temperature $\left(10^{\circ} \mathrm{C}, 25^{\circ} \mathrm{C}\right.$ and $40^{\circ} \mathrm{C}$ ). These changes are related with the different state of PCM inside the mortars pores. Thus, when the PCM is in the solid state, the amount of water absorbed decreases. It, was verified that the reference mortars presented higher values of water absorption, which shows that PCM does not move to outside of the mortar matrix.

According to flexural and compressive strengths, it can be concluded that he incorporation of non-encapsulated PCM did not cause significant changes in the mortars mechanical behavior. On the other hand, the developed mortars presented the highest resistance class, taking into account the compressive behavior.

\section{Acknowledgements}

The authors acknowledge the Portuguese Foundation for Science and Technology (FCT) for the financial support of PhD scholarship SFRH/BD/95611/2013.

\section{References}

[1] S.A. Memon, Phase change materials integrated in building walls: a state of the art review, Renewable Sustainable Energy Rev. 31 (2014) 870-906.

[2] N. Soares, J. Costa, A. Gaspar, P. Santos, Review of passive PCM latent heat thermal energy storage systems towards buildings energy efficiency, Energy Build. 59 (2013) 82-103.

[3] S. Bilgen, Structure and environmental impact of global energy consumption, Renewable Sustainable Energy Rev. 38 (2014) 890-902.

[4] S. Cunha, J. Aguiar, F. Pacheco-Torgal, Effect of temperature on mortars with incorporation of phase change materials, Constr. Build. Mater. 98 (2015) 89101. 
[5] Y. Zhang, G. Zhou, K. Lin, K. Zhang, H. Di, Application of latent heat thermal energy storage in buildings: state-of-the-art and outlook, Build. Environ. 42 (2007) 2197-2209.

[6] B. Zalba, J. Marín, L. Cabeza, H. Mehling, Review on thermal energy storage with phase change: materials, heat transfer analysis and applications, Appl. Therm. Eng. 23 (2003) 251-283.

[7] L. Cabeza, A. Castell, C. Barreneche, A. Gracia, A. Fernández, Materials used as PCM in thermal energy storage in buildings: a review, Renewable Sustainable Energy Rev. 15 (2011) 1675-1695.

[8] V. Tyagi, S. Kaushik, S. Tyagi, T. Akiyama, Development of phase change materials based microencapsulated technology for buildings: a review, Renewable Sustainable Energy Rev. 15 (2011) 1373-1391.

[9] G. Fang, F. Tang, L. Cao, Preparation, thermal properties and applications of shape-stabilized thermal energy storage materials, Renewable Sustainable Energy Rev. 40 (2014) 237-259.

[10] D.W. Hawes, D. Banu, D. Feldman, Latent heat storage in concrete, Sol. Energy Mater. 19 (1989) 335-348.

[11] D.W. Hawes, D. Feldman, Absorption of phase change materials in concrete, Sol. Energy Mater. Sol. Cells 27 (1992) 91-101.

[12] H. Kaasinen, The absorption of phase change substances into commonly used building materials, Sol. Energy Mater. Sol. Cells. 27 (1992) 173-179.

[13] S. Cunha, J.B. Aguiar, V.M. Ferreira, A. Tadeu, Mortars based in different binders with incorporation of phase change materials: physical and mechanical properties, Eur. J. Environ. Civ. Eng. 19 (2015) 1216-1233.

[14] A.K. Athienitis, C. Liu, D. Hawes, D. Banu, D. Feldman, Investigation of the thermal performance of a passive solar test-room with wall latent heat storage, Build. Environ. 32 (1997) 405-410.

[15] L. Shilei, Z. Neng, F. Guohui, Impact of phase change wall room on indoor thermal environment in winter, Energy Build. 38 (2006) 18-24.

[16] K. Darkwa, P. O'Callaghan, D. Tetlow, Phase-change drywalls in a passive-solar building, Appl. Energy 83 (2006) 425-435.

[17] C. Lai, R.H. Chen, C. Lin, Heat transfer and thermal storage behaviour of gypsum boards incorporating micro-encapsulated PCM, Energy Build. 42 (2010) 12591266.

[18] A.G. Entrop, H.J.H. Brouwers, A.H.M.E. Reinders, Experimental research on the use of micro-encapsulated phase change materials to store solar energy in concrete floors and to save energy in Dutch houses, Sol. Energy 85 (2011) 1007-1020.

[19] S. Cunha, V. Alves, J.B. Aguiar, V.M. Ferreira, Use of phase change materials microcapsules in aerial lime and gypsum mortars, Cem. Wapno Beton (2012) 17-21 (Special Issue).

[20] S. Cunha, J.B. Aguiar, V.M. Ferreira, A. Tadeu, Influence of adding encapsulated phase change materials in aerial lime based mortars, Adv. Mater. Res. 687 (2013) 255-261.
[21] M. Ahmad, A. Bontemps, H. Sallée, D. Quenard, Thermal testing and numerica simulation of a prototype cell using light wallboards coupling vacuum isolation panels and phase change material, Energy Build. 38 (2006) 673-681.

[22] A.M. Borreguero, M. Carmona, M.L. Sanchez, J.L. Valverde, J.F. Rodriguez, Improvement of the thermal behaviour of gypsum blocks by the incorporation of microcapsules containing PCMS obtained by suspension polymerization with an optimal core/coating mass ratio, Appl. Therm. Eng. 30 (2010) $1164-$ 1169.

[23] P. Principi, R. Fioretti, Thermal analysis of the application of PCM and low emissivity coating in hollow bricks, Energy Build. 51 (2012) 131-142.

[24] S. Cunha, J.B. Aguiar, V.M. Ferreira, A. Tadeu, Influence of the type of phase change materials microcapsules on the properties of lime-gypsum thermal mortars, Adv. Eng. Mater. 16 (2014) 433-441.

[25] Rubitherm, RT22HC, <http://www.rubitherm.eu/en/index.php/ productcategory/organische-pcm-rt>, 2015 (accessed December, 2015).

[26] European Committee for Standardization (CEN), EN 1015-3:2004, Methods of Test for Mortar for Masonry - Part 3: Determination of Consistence of Fresh Mortar (by Flow Table), 2004.

27] European Committee for Standardization (CEN), EN 1015-11:1999, Methods of Test for Mortar for Masonry - Part 11: Determination of Flexural and Compressive Strength of Hardened Mortar, 1999.

[28] European Committee for Standardization (CEN), EN 1015-18:2002, Methods of Test for Mortar for Masonry - Part 18: Determination of Water Absorption Coefficient due to Capillary Action of Hardened Mortar, 2002.

[29] National Laboratory of Civil Engineering (LNEC), Specification E 394. ConcreteDetermination of Water Absorption by Immersion, 1993 (in Portuguese).

[30] M. Anjos, A. Camões, C. Jesus, F. Duarte, Hydration assessment of cement pastes with high levels of mineral additions, Engenharia Civil UM 44 (2012) 41-58 (in Portuguese).

[31] J.I. Bhatty, K.J. Reid, Use of thermal analysis in the hydration studies of a type 1 portland cement produced from mineral tailings, Thermochim. Acta 91 (1985) 95-105.

32] L. Alarcon-Ruiz, G. Platret, E. Massieu, A. Ehrlacher, The use of thermal analysis in assessing the effect of temperature on a cement paste, Cem. Concr. Res. 35 (2005) 609-661.

[33] G. Baert, S. Hoste, G. Schutter, N. Belie, Reactivity of fly ash in cement paste studied by means of thermogravimetry and isothermal calorimetry, J. Therm. Anal. Calorim. 94 (2008) 485-492.

[34] D. Dollimore, J. Gupta, S. Lerdkanchanaporn, S. Nippani, A thermal analysis study of recycled portland cement concrete (RPCC) aggregates, Thermochim. Acta 357 (2000) 31-40.

[35] Portuguese Institute for Quality (IPQ), NP EN 998-1:2013, Specification for Masonry Mortars - Part 1: Plastering Mortars for Interior and Exterior, 2013 (in Portuguese). 